\title{
GEGURITAN SEBUN BANGKUNG KAJIAN BENTUK, FUNGSI DAN MAKNA
}

\author{
I Wayan Rinda Suardika \\ Jurusan Pedalangan, Fakultas Seni Pertunjukan, \\ Institut Seni Indonesia Denpasar, Indonesia
}

\begin{abstract}
The research is aimed to find out the form, function, and the meaning of Geguritan Sebun Bangkung in social and cultural Hinduism community in Bali. in this research, the writer used structural theory, functional theory and semiotics theory. The structural theory is used to confirm the form, and the narrative structural of the literature, while the functional theory is used to analyze its function. In determining the meaning at the Geguritan Sebun Bangkung text, the semiotics theory is applied. These are methods used in this research: 1) In collecting data, it's used library study, interview and completed with taking notes technique; 2) In analyzing data, qualitative descriptive method is used and completed with translation technique. After analyzing data, it's found that Geguritan Sebun Bangkung contains 9 texts. Geguritan Sebun Bangkung consist of 16 pupuh which has followed its own rules (padalingsa: word rules, numerical rules and rhyme rule) in Medium Balinese language with some Old Javanese words.
\end{abstract}

Keywords: Bentuk, fungsi, and makna geguritan Sebun Bangkun

Hakikat kebudayaan Bali adalah kebudayaan sebagai wujud pengamalan ajaran agama Hindu di Bali. Agama Hindu adalah jiwa dari kebudayaan Bali. Inti ajaran agama Hindu adalah Sanatana Dharma atau kebenaran yang kekal dan abadi. Sanatana Dharma itu adalah: satyam, siwam, dan sundaram. Maksudnya membangun Bali seharusnya dimulai dengan menegakkan kebenaran (satyam) dan kesucian yang telah terpatri dalam wujud kebudayaan Bali. Tegaknya kebenaran dan kesucian dibangun keharmonisan dan keindahan (sundaram) yang sejati di Bali. Keharmonisan itu dibangun oleh sikap hidup yang seimbang (berbakti pada Tuhan, mengabdi sesama umat manusia, dan menyayangi alam berdasarkan Yadnya). Sikap hidup seimbang itulah yang disebut dengan Tri Hita Karana 
(Putra, 1987:68). Tatanan hidup seperti ini telah dibangun oleh Maha Resi Markandya pada abad VIII, Mpu Kuturan pada abad XI, dan Dang Hyang Nirartha pada abad XV (Putra, 1987:54; Soebandi, 1983:16).

Dalam sejarah perkembangan Agama Hindu di Bali disebutkan: setelah kerajaan Majapahit runtuh (1478 Masehi) Dang Hyang Nirartha pindah menuju Pasuruhan terus ke Blambangan, dari Blambangan lalu menuju Bali turun di Pantai Purancak (Putra, 1987 :68). Bagi umat Hindu di Bali nama Dang Hyang Nirartha, Dang Hyang Dwijendra adalah nama yang sangat terkenal dan dikenal dengan mendalam terutama oleh para sulinggih agama Hindu (Tuuk, 1899:520). Sebagai tokoh agama, Dang Hyang Nirartha telah memperkaya dan memperkuat akar-akar agama Hindu di Bali (Sugriwa, 1974:56).

Dang Hyang Nirartha banyak menuangkan ajaran-ajaran agama melalui karya sastra tulis (Soebandi, 2002:23). Sastra tulisan merupakan bagian yang tidak dapat dipisahkan dari sastra lisan kerena tulisan adalah salah satu cara atau alat untuk men-dokumentasikan karya-karya masyarakat agar bisa diwariskan kepada generasi penerusnya. Naskah lontar merupakan salah satu peninggalan tertulis hasil kebudayaan masa lampau. Naskahnaskah itu disimpan dan dipelihara oleh generasi yang mewarisi karena di dalamnya memuat berbagai macam nilai yang luhur. Di dalam naskahnaskah kesusastraan lontar terdapat berbagai ajaran filsafat agama (tatwa), ethika (tata susila), dan ritual (upacara-upakara).

Salah satu bentuk naskah adalah geguritan yang merupakan karya sastra sarat dengan nilai-nilai luhur budaya bangsa dan sekaligus merupakan khasanah budaya bangsa yang ada di Bali. Geguritan ini diperkirakan muncul sesudah zaman Gelgel, yakni pada zaman Klungkung. Pernyataan ini sejalan dengan pendapat Suastika (1997:2) yang menyatakan bahwa pada zaman Klungkung karya sastra Jawa Kuno digubah ke dalam genre baru yang disebut geguritan.

Berdasarkan uraian tersebut, maka dalam penelitian ini akan dikaji salah satu geguritan yakni Geguritan Sebun Bangkung, karya sastra peninggalan Dang Hyang Nirartha. Geguritan Sebun Bangkung memiliki nilai filosofis yang tinggi (Dewa Tatwa, Atma Tatwa, Karmapala Tatwa, Punarbawa Tatwa, Moksa Tatwa). Geguritan Sebun Bangkung digubah dalam bentuk puisi menggunakan bahasa Bali Kepara dan bahasa Jawa Kuno diikat oleh padalingsa. Sehingga menimbulkan nilai estetik yang tinggi, bukan saja bagi pelaku sastra, tetapi bagi penikmatnya juga. Namun, kenyataan pada umumnya umat Hindu belum mampu memahami, menghayati, dan mengamalkan ajaran-ajaran yang terkandung di dalamnya, terutama yang terkait dalam hidup dan kehidupan sehari-hari. Hal ini ditunjukkan oleh karena masih banyak adanya konflik-konflik adat, lembaga keumatan belum bersatu sebagai sandaran umat sedharma. 
Berdasarkan uraian tersebut timbul permasalahan: 1) Bagaimana bentuk Geguritan Sebun Bangkung, 2) Apa fungsi Geguritan Sebun Bangkung dalam kehidupan sosial budaya masyarakat Bali, dan 3) Apa makna yang tersirat dalam Geguritan Sebun Bangkung dalam hubungannya dengan kehidupan sosial budaya masyarakat Bali.

Adapun tujuan penelitian ini: 1) Untuk mengetahui bentuk dan struktur Geguritan Sebun Bangkung, 2) Untuk mengetahui fungsi Geguritan Sebun Bangkung dalam kehidupan sosial budaya masyarakat Bali, dan 3) Untuk mengetahui makna Geguritan Sebun Bangkung dalam hubungannya dengan kehidupan sosial budaya masyarakat Bali.

Manfaat teoritis dari penelitian: dapat memperkaya khasanah budaya khususnya karya sastra klasik. Sedangkan manfaat praktis: masyarakat dapat memahami dan menerapkan nilai-nilai luhur yang terkandung dalamnya, terutama aspek tatwa, etika dan upacara, serta dekat pada masyarakat penikmat sastra, khususnya kelompok-kelompok pesantian.

\section{KAJIAN PUSTAKA}

Geguritan Sebun Bangkung adalah karya sastra dalam bentuk narasi yang dibentuk oleh puisi. Sama halnya dengan karya sastra yang lain, bahwa geguritan ini adalah karangan yang menggunakan tembang atau pupuh macapat.

Geguritan berasal dari kata gurit yang artinya tulisan, komposisi khususnya puisi.Anggurit artinya menulis sesuatu, mengubah sesuatu (Mulder dan Robson, 1997:320). Dalam kamus bahasa Bali- Indonesia (Warsito,1978:223), gurit artinya gubah, karang, sadur. Geguritan artinya gubahan, saduran, karangan. Geguritan artinya gubahan cerita yang berbentuk tembang (pupuh). Geguritan itu adalah merupakan karya sastra yang dibangun oleh pupuh dan diikat oleh peraturan padalingsa. Yang mempunyai sistem konvensi sastra cukup ketat (Ganing, 2003:7). Sedangkan yang dimaksud dengan pupuh adalah padalingsa, di mana padalingsa ini dapat menimbulkan melodi atau lagu yang lazim disebut dengan gending.

Setiap pupuh mempunyai padalingsa sendiri-sendiri. Jadi dapat disimpulkan bahwa geguritan adalah gubahan cerita yang berbentuk tembang diikat oleh padalingsa. Sedangkan kata Sebun Bangkung terdiri dari kata Sebun dan Bangkung. Kata sebun dalam bahasa bali berarti sarang atau rumah. Seperti sebun kedis yang berarti sarang burung. Sedangkan kata bangkung dalam bahasa Bali yang berarti induk babi betina. Jadi secara etimologi kata Sebun Bangkung berarti sarang atau rumah induk babi (Team ,1978:506).

Kemudian kalau dihubungkan judul dengan isi lontar Ge-guritan Sebun Bangkung tampak tak ada hubungannya sama sekali. Dalam lontar Geguritan Sebun Bangkung sama sekali tidak ada menyinggung atau 
menyebutkan masalah sarang atau induk babi. Mestinya suatu judul karya sastra merupakan puncak dari isi karangan bersangkutan. Seperti misalnya: geguritan Basur, maka Basur nama tokoh geguritan itu. Demikian pula geguritan Dukuh Siladri, maka Dukuh Siladri yang merupakan tokoh utama dalam geguritan yang bersangkutan. Dengan demikian, jelas bahwa kata Sebun Bangkung sebagai nama karya sastra tidaklah nama yang sebenarnya menurut arti kata.

Pengertian kata Sebun Bangkung lebih mengarah pada pengertian maknawi atau terminologi. Dalam karya sastra Bali ada kecenderungan pengarang untuk membuat judul atau nama tidak menggunakan nama atau arti kata yang sebenarnya, tetapi sering menggunakan nama samaran atau kata-kata dalam arti kias. Misalnya, karya-karya Ida Pedanda Made Sidemen beliau mempergunakan nama samaran dalam lontar, antara lain: Tan Arsa, Tan Sukeng hati. Tan arsa, Tan sukeng hati dalam bahasa Bali berarti Sing demen. Kata Sing demen inilah berdekatan dengan kata Sidemen (Agastya,1994:21).

Kata Sebun memiliki arti kias yang berarti himpunan dan kata Bangkung terdiri dari dua kata yaitu Bang dan Kung. Bang yang berarti Brahman, yaitu Tuhan Yang Maha Esa. Sedangkan Kung berarti asmara atau cinta. Jadi Bangkung berarti cinta pada Tuhan. Tuhan bersifat maha bijaksana (Love of Wisdom) Cinta kepada kebijaksanaan itu adalah filsafat. Dengan demikian, dapat dikatakan bahwa yang disebut Sebun Bangkung adalah kumpulan atau himpunan ajaran-ajaran filsafat Ketuhanan (Arnawa, 1992:18).

Untuk mengkaji lebih jauh tentang Geguritan Sebun Bangkung dipergunakan pula beberapa tulisan seperti: Geguritan Sudamala oleh I Ketut Nama (2001), Geguritan Gunatama oleh Ni Nyoman Ganing (2003) dan Wacana Geguritan Brayut dalam kontek masyarakat Bali oleh Tjok Istri Putra Handriyani (2003). Semua tulisan tersebut dipakai acuan untuk menemukan konsep geguritan serta teori-teori yang sesuai dalam menganalisis bentuk, fungsi serta makna Geguritan Sebun Bangkung, dalam konteks kehidupan sosial masyarakat Bali.

Sedangkan tulisan yang berjudul Ulasan Dwijendra Tatwa (Agastya, 1983) yang memaparkan tentang sejarah perkembangan kesusastraan Bali (zaman Gelgel) kami pergunakan sebagai acuan untuk melihat makna dari Geguritan Sebun Bangkung terkait dengan kehidupan sosial masyarakat Bali.

\section{METODE PENELITIAN}

Penelitian tentang Geguritan Sebun Bangkung menggunakan metode penelitian kualitatif yang dipayungi oleh ilmu kajian budaya (cultural 
studies) terutama kajian budaya religi dan kajian budaya makna simbolik. (Sepradley, 1987:121).

Teknik pengumpulan data melalui: observasi yaitu mengamati langsung data di Pusat Dokumentasi Budaya Bali (Pusdok) untuk mendapatkan data primer. Studi pustaka untuk menelusuri teks-teks yang ada hubungannya dengan Geguritan Sebun Bangkung, serta melalui wawancara untuk menggali informasi-informasi dari tokoh-tokoh masyarakat terutama terkait dengan analisis fungsi dan makna Geguritan Sebun Bangkung dalam hubungannya dengan kehidupan sosial budaya menyangkut Bali. Sedangkan metode analisis data digunakan metode kualitatif yang bersifat deskriptif yang dibantu dengan teknik terjemahan.

\section{HASIL DAN PEMBAHASAN}

Naskah Geguritan Sebun Bangkung yang dipergunakan sumber penelitian adalah naskah koleksi Pusat Dokumentasi Budaya Bali (Pusdok) dengan nomor kropak 6/XX/I/Dokbud. Mempergunakan huruf Bali memakai bahasa Jawa Kuno dengan kosa basa bahasa Bali Kepara. Dalam khasanah kesusastraan Bali naskah Geguritan Sebun Bangkung terdiri dari 9 teks (Teks Tutur Geguritan Sebun Bangkung, Teks Prembon, Teks Kembanging Langit, Teks Rumakseng Wengi, Teks Tutur Saraswati, Teks Guyu Pasaja, Teks Bagendali, Teks Nabi, dan Teks Cowak)

Geguritan Sebun Bangkung mempergunakan 16 pupuh dan masingmasing pupuh diikat oleh padalingsa (guru gatra, guru wilangan, dan guru swara), dengan jumlah bait 463 bait.

Teks I, mempergunakan Pupuh Pucung, berisi ajaran tentang lahirnya aksara wreastra, swalalita, dan modre, serta peranan warga aksara dalam diri manusia untuk mencapai kelepasan hidup. Teks II (Prembon) mempergunakan Pupuh Durma yang berisikan ajaran Çiwa Tiga. Teks III (Kembanging Langit) mempergunakan Pupuh Sinom, Pangkur, dan Semarandana, berisi tentang ajaran agama Islam yang sesungguhnya mempunyai kesamaan dengan agama lain dalam hakekat tujuan, namun berbeda dalam aspek tata cara pelaksanaannya. Teks IV (Rumakseng Wengi) mempergunakan Pupuh Dangdang, berisi ajaran pengraksa jiwa. Teks V (Tutur Saraswati) mempergunakan Pupuh Durma, Sinom, berisikan ajaran tentang Sang Hyang Saraswati bersama Sang Hyang Guru Reka, dan Sang Hyang Tiga Adnyana menciptakan tutur di aksara tanpa sastra dalam membina kehidupan manusia. Teks VI (Guyu Pasaja) mempergunakan Pupuh Ginada berisi ajaran tata susila. Teks VII (Bhagendali), mempergunakan pupuh: Pupuh Durma, Dangdang Gula, dan Sinom, berisi ajaran tentang kelahiran Amad-Muhamad. Teks VIII (Nabi) mempergunakan pupuh: Pupuh Dangdang, Sinom, dan Pangkur, berisi kritik terhadap ajaran 
Islam bagi para santri. Teks IX (Cowak) mempergunakan Pupuh Demung, berisi tentang kritik-kritik yang disampaikan dalam kehidupan para pendeta.

\section{Bentuk dan Struktur Geguritan Sebun Bangkung}

Karya sastra menurut fungsinya dibedakan dalam bentuk puisi, prosa, dan roman (Luxemburg, dkk, 1984:116). Geguritan Sebun Bangkung mempunyai ciri bentuk puisi yang bersifat naratif dan masing-masing pupuh diikat oleh padalingsa, yaitu banyaknya baris dalam tiap-tiap bait, banyaknya suku kata dalam tiap-tiap baris dan bunyi akhir dalam tiap-tiap baris (Agastia, op.cit. p. 8). Pupuh-pupuh yang membangun Geguritan Sebun Bangkung :

Teks I (Geguritan Sebun Bangkung) : Pupuh Pucung

Teks II (Prembon) : Pupuh Durma

Teks III (Kembanging Langit) : Pupuh Sinom, Pangkur,

Semarandana

Teks IV (Rumakseng Wengi) : : Pupuh Dandang

Teks V (Tutur Saraswati) : Pupuh Durma, Sinom

Teks VI (Guyu Pasaja) : : Pupuh Ginada

Teks VII (Bagendali) : Pupuh Durma,

Dandang

Gula, Sinom

Teks VIII (Nabi)

: Pupuh Dandang, Sinom, Pangkur

Teks IX (Cowak)

: Pupuh Demung

Geguritan Sebun Bangkung digubah dengan memperguna-kan bahasa Bali dan bahasa Jawa Kuno. Pemakaian bahasa Bali dalam Geguritan Sebun Bangkung diwarnai dengan anggah-ungguhing basa (Tinggen, 1994:3). Kemudian untuk memenuhi kaidah padalingsa pupuh, pengarang memanfaatkan stalistika yang meliputi: 1) pemanfaatan aspek bunyi, 2) pemilihan kosa kata, 3) pemanfaatan kata sapaan dan kata seru, dan 4) pemanfaatan gaya bahasa. Sedangkan struktur naratif Geguritan Sebun Bangkung meliputi sinopsis dari masing-masing teks, order atau rangkaian peristiwa yang digunakan narator sebagai pencerita. Alur (plot) yaitu rangkaian peristiwa yang meliputi tahapan pengenalan (eksposisi), pembibitan, konflik, klimaks, dan penyelesaian. Geguritan Sebun Bangkung merupakan himpunan dari beberapa teks dengan tema yang berbeda, dengan demikian tokoh-tokoh utama pada masing-masing teks ada yang berbeda dan ada yang sama dengan nama yang berbeda, demikian pula tokoh-tokoh sekunder dan tokoh komplementernya.

Sudjiman (1984:46) menyebut latar merupakan salah satu unsur yang cukup penting dalam struktur sebuah karya sastra. Latar memiliki 3 unsur, yakni unsur tempat, waktu, dan sosial. Dalam menganalisis latar dalam 
Geguritan Sebun Bangkung mengacu pada pendapat di atas. Sedangkan untuk menentukan tema dalam Geguritan Sebun Bangkung, peneliti mengacu pada Keraf (1983:107) yaitu perumusan dari topik yang dijadikan landasan pembicaraan untuk mencapai tujuan. Sehingga tema yang dapat ditentukan adalah: 1) Ajaran tentang Ketuhanan (Widi Tatwa), 2) Ajaran Kanda Pat Sari, 3) Ajaran Pangraksa Jiwa, 4) Ajaran kesusilaan, dan 5) Ajaran kelepasan (Tutur Kemoksan).

\section{Fungsi Geguritan Sebun Bangkung}

Fungsi Geguritan Sebun Bangkung terhadap kehidupan sosial budaya masyarakat Hindu di Bali meliputi fungsi Ketuhanan (Widhi Tatwa), fungsi moralitas (etika), fungsi upacara (rituil), fungsi pendidikan, fungsi estetika, dan fungsi sosial budaya. Fungsi Ketuhanan dapat dilihat lewat tokoh-tokoh dewa-dewa, bhatara, seperti Dewa Parama Siwa, Dewa-dewa Panca Dewata, Dewata Nawa Sanga, Sang Hyang Licin, Sang Hyang Guru Reka, Hyang Durga, bahkan dalam Teks Nabi ada sebutan Allah. Semua itu adalah Tuhan itu sendiri atau manifestasi kekuasaan Tuhan Yang Maha Esa sesuai dengan fungsinya masing-masing. Fungsi pendidikan moral (etika) dapat dilihat atau tecermin pada tokoh Jero Dukuh ketika memberikan ajaran agama (sastra) kepada tokoh I Made Tanu dan I Gede Togag, seperti yang tersirat pada Teks Guyu Pasaja. Fungsi upacara (ritual) dapat dilihat hanya berkisar pada upacara-upacara yang berhubungan dengan kelahiran manusia dalam ajaran Kanda Empat (Geguritan Sebun Bangkung, bait 96). Fungsi pendidikan dapat dilihat dari metode pendidikan malajah sambilang magending ("belajar sambil bernyanyi"). Dengan membaca sebuah lontar, dididik untuk membaca huruf Bali, memahami bahasa yang dipergunakan, serta mencari nilai-nilai filosofis yang terkandung dalam kesusastraan tersebut sehingga dapat menjauhi budaya anak muda seperti Teddy Boys, Hippies, Hell Angels (Tester, 2003:154). Fungsi estetika, pengungkapan rasa estetik tersirat pada kemampuan pengarang untuk mengungkapkan rasa keindahannya lewat tokoh-tokoh Dewi Saraswati, Kawi Swara, Dewa Kama, Dewi Ratih. Kemudian ungkapan rasa keindahan lewat sajak keindahan dalam diri seorang gadis, dalam bunga, deburan ombak (Geguritan Sebun Bangkung, Lb. 25a, bait 198). Di samping itu pemakaian berbagai macam pupuh dalam Geguritan Sebun Bangkung sehingga dapat dinyanyikan sesuai dengan watak, fungsi serta misi yang dibawa untuk menghibur pendengar, maupun yang menyanyikan. Fungsi sosial budaya, fungsi ini dapat terlihat dalam mengimplementasikan ajaran melalui megeguritan. Dalam megeguritan jelas ada aktivitas manusia baik secara individu maupun berkelompok dalam bentuk Sekaa Santi, seorang terhibur, menghibur, menghilangkan rasa gundah. Melalui kegiatan ini pula ada aktivitas saling tolong menolong sesama umat tatkala melakukan upacara-upacara keagamaan disuguhkan nyanyian (gending-gending) oleh sesama Sekaa Santi. Hal ini sesuai dengan 
pendapat Horace (Welled dan Waren, 1990:25) yang menyebutkan bahwa karya sastra dalam masyarakat berfungsi dulce (hiburan atau menghibur) dan utile (bermanfaat).

\section{Makna Geguritan Sebun Bangkung}

Makna Geguritan Sebun Bangkung dalam kehidupan sosial budaya masyarakat Bali adalah: 1) Makna religius: melaksanakan dharma gita (geguritan) berarti telah melaksanakan hal-hal yang bersifat keagamaan. Oleh karena ajaran-ajaran yang dituangkan dalam Geguritan Sebun Bangkung umumnya mengandung aspek tatwa, etika dan upacara, 2) makna kelepasan atau kemoksan disampaikan dalam ajaran (tutur) Genta Pinara Pitu, Budha kecapi, dan Kuranta Bolong. Demikian pula ajaran Pangraksa Jiwa dikuasai oleh Bhagendali, sehingga ia tahu jalan terbaik untuk melepaskan diri guna mencapai moksa, 3) Makna pengendalian diri, tersirat dalam Tutur Nabhi: "Jika engkau berkedudukan sebagai santri, harus selalu waspada Anakku, karena musuh selalu mengelilingi, di bawah juga di atas, berkeliaran", 4) Makna estetika, makna ini terlukis dalam Geguritan Sebun Bangkung sebagai karya sastra yang berbentuk puisi (tembang), memakai aturan padalingsa, pemanfaatan bentuk-bentuk pupuh, bahasa (anggahungguh basa), pemanfaatan aspek bunyi, pemilihan kosa kata, kata sapaan serta pemanfaatan gaya bahasa sehingga sarat dengan makna estetik, dan 5) Makna karma phala, terlukis pada Geguritan Sebun Bangkung seperti dalam nasehat Jero Dukuh: "Walau kini hidup nyasar, jangan ikut kebingungan, dharma itu laksanakan, tekun belajar, niscaya pahalanya di kemudian hari diterima".

\section{SIMPULAN}

Berdasarkan hasil dan pembahasan penelitian ini dapat disimpulkan hal-hal sebagai berikut: Geguritan Sebun Bangkung dibentuk oleh 9 teks, dibangun oleh 16 pupuh, terdiri dari 463 bait, masing-masing pupuh yang menjalin cerita dalam Geguritan Sebun Bangkung diikat oleh aturan padalingsa, mempergunakan bahasa Bali Kepara bercampur dengan kosa kata Jawa Kuno, memakai anggah-ungguh basa. Untuk memenuhi kaidah padalingsa pupuh pengarang memanfaatkan stilistika yang meliputi pemanfaatan aspek bunyi, pemilihan kosa kata, kata sapaan, pemanfaatan gaya bahasa.

Fungsi Geguritan Sebun Bangkung dalam kehidupan sosial masyarakat Bali adalah sebagai didaktis religius yang meliputi fungsi ketuhanan, fungsi pendidikan moralitas, fungsi upacara, estetika, dan sosial budaya. Sedangkan makna Geguritan Sebun Bangkung adalah: 1) makna religius yaitu melaksanakan dharma gita, meliputi aspek tatwa, etika, dan upacara, 2) makna kemoksan disampaikan dalam ajaran (tutur) Genta Pinara 
Pitu, Budha Kecapi, dan Kuranta Bolong, 3) makna pengendalian diri, tersirat dalam Tutur Nabhi, 4) makna estetika, dan 5) makna Karma Phala.

\section{DAFTAR RUJUKAN}

Agastya. 1994. Ida Pedanda Made Sidemen Pengarang Basa Bali Abad Ke 20. Denpasar: Yayasan Dharma Sastra. .1983. Ulasan Dwijendra Tatwa.Denpasar: Yayasan Dharma Sastra.

Ganing, Ni Ketut. 2003. Geguritan Gunatama. Denpasar, PT. Percetakan Bali.

Keraf, Gorys. 1983. Argumentasi dan Narasi. Jakarta: Gramedia.

Luxemburg, J. van. 1984. Pengantar Ilmu Sastra (Terjemahna Hartoko). Jakarta

Putra, I Gusti Agung Gde. 1987. Sejarah Perkembangan Agama Hindu di Bali. Penerbit: Pemda Tk I Bali.

Soebandi, I Ketut. 1983. Sejarah Pembangunan Pura-pura di Bali. Denpasar: CV Kayumas.

—. 2002. Pandita Sakti Wawu Rawuh. Denpasar: Pustaka Manik Geni.

Suastika, I Made. 1997. Calonarang dalam Tradisi Bali. Yogyakarta: Duta Wacana University Press.

Sudjiman, Panuti. 1984. Kamus Istilah Sastra. Jakarta: Gramedia.

Sugriwa, I Gusti Bagus. 1974. Pemargan Dang Hyang Nirartha di BaliPemargan Dang Hyang Nirartha di Bali. Denpasar: Parisada Hindu Dharma.

Supradley, James, P. 1987. Metode Etnografi. Yogyakarta: Tiara Wacana.

Tester, Keith. 2003. Seri Cultural Studies, Media, Budaya, dan Moralitas. Juxtapose dan Kreasi Wacana.

Tinggen. 1994. Aneka Sari Gending-gending Bali. Singaraja: Rhineka Dewata.

Tuuk, Van der. 1899. Kawi Balinesch Nederlandsch Woodenboek. Batavia Londsdrukry.

Wellek dan Warren. 1990. Teori Kesusastraan (Terjemahan Melani Budianta). Jakarta: Gramedia. 